\title{
EFfect of Moisture on Mechanical BeHaVior OF GRANULAR MATERIAL IN INITIAL LABORATORY AND Mechanical Tests
}

\author{
Przemyslaw ROKITOWSKI ${ }^{1}$, Marcin GRYGIEREK ${ }^{2}$ \\ ${ }^{1}$ Department of Geotechnics and Roads, Faculty of Civil Engineering, Silesian University of Technology, \\ ul. Akademicka 5, 44-100 Gliwice, Poland \\ ${ }^{2}$ Department of Geotechnics and Roads, Faculty of Civil Engineering, Silesian University of Technology, \\ ul. Akademicka 5, 44-100 Gliwice, Poland
}

przemyslaw.rokitowski@polsl.pl, Marcin.Grygierek@polsl.pl

DOI: 10.31490/tces-2018-0005

\begin{abstract}
In this article authors present results of initial laboratory tests and further numerical analyses using finite element method (FEM) and back - calculation method. Laboratory tests are based on trial loadings of granular material in different moisture conditions. $\mathrm{Nu}$ merical analyses were obtained in FEM software using Coulomb - Mohr model of tested material. Presented results are the part of wider research program in which the main aim is to evaluate the influence of variable moisture content of granular materials used in road pavement structures on their fatigue life and in Life Cycle Assessment ( $L C A)$.
\end{abstract}

\section{Keywords}

Moisture content, trial loading, granular material, finite element method, back - calculation, small-scale tests.

\section{Introduction}

Assurance of strong and solid foundation is one of the most important goals at the designing and execution process. For linear structures such as railway tracks, highway or state roads the role of foundation is fulfilled by subsoil which is characterized by bearing capacity frequently equated to modulus of elasticity $(E)$. Alterations of moisture content of both cohesive and non cohesive soils have a significant influence on mechanical behavior of analyzed material, particularly on behavior of subsoils under loading [1]. The change in moisture content affects parameters such as internal friction angle $(\varphi)$, cohesion $(c)$ and modulus of elasticity $(E)$ of both cohesive and non-cohesive soils. It is known that excess moisture content in unbound layers of road pavement structures or subsoil reduces suction pressure resulting in decrease of values of $E$ moduli or shear strength which results in consequent deterioration in pavement structural performance [2, [3]. Following numerously investigations on the behavior of pavement structures it is proved that excess water accelerates the deterioration processes of the pavement structures causing different types of damages in respective layers [4, [5]. High moisture content in subsoil as well as in unbound granular materials (UGMs) causes i.e. increase of pavement deflections and faster generation of permanent deformations and rutting [6], 7], 8]. Significant effect of variable moisture content on mechanical properties is observed in materials with high proportion of fines and densely graded [9]. Alteration of mechanical parameters of particular pavement layers, connected with process of increasing moisture content, leads to considerable reduction of safety and driving comfort for road users. In this work authors present results of initial laboratory tests executed on a test stand and further numerical analyses carried out in student version of ZACE Z_Soil 2014 software [10].

\section{Small - Scale Laboratory Tests}

Initial laboratory tests were executed in small - scale on a test stand in Laboratory of Civil Engineering Faculty on Silesian University of Technology. Tests were divided into two groups: investigation of non - cohesive medium (sandy material) $l$ and trial loadings. The main aim of the investigation part of tests was to ob- 


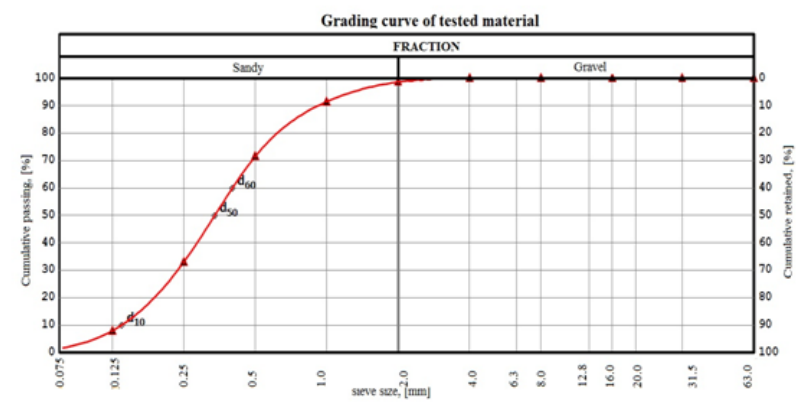

Fig. 1: Grading curve of tested sand

tain key parameters of analyzed soil: grain composition, optimum moisture content, dry density, cohesion and internal friction angle in different moisture conditions. The second part of tests focused on observation of vertical displacement under a static load generated by VSS hydraulic equipment and loading plate. Main laboratory tests consisted of small - scale trial loadings of sand in different moisture conditions and were preceded by investigation of tested granular material in sieve analysis, test in Proctor apparatus and shear test in direct shearing apparatus. Results obtained in the tests were used in numerical analyses using finite element method and back-calculation method. Numerical model of laboratory tests was built using Coulomb Mohr (C - M) model of tested medium and was preceded by studies aimed to obtain the best dimensions of mesh, impact of boundary conditions in small - scale tests and conditions of model similarity [11. Numerical modeling was executed to back - calculate mechanical parameters of soil and to find the best fitting of the deformation - applied load relationship.

\subsection{Sieve Analysis}

The material selected for initial laboratory tests was sand. Sieve analysis was executed to obtain grain composition of material and to draw the grading curve. Specimen before the sieve analysis was rinsed to obtain silt fraction $(\sharp<0.063 \mathrm{~mm})$. The mass of specimen was equal to $1501.1 \mathrm{~g}$ and after rinsing and drying to constant mass it decreased to $1489.5 \mathrm{~g}$. To perform the test a set of 15 sieves was used: $\sharp 80 \mathrm{~mm}, \sharp 63 \mathrm{~mm}$, $\sharp 31.5 \mathrm{~mm}, \sharp 20 \mathrm{~mm}, \sharp 16 \mathrm{~mm}, \sharp 12.8 \mathrm{~mm}, \sharp 8 \mathrm{~mm}, \sharp 5.6$ $\mathrm{mm}, \sharp 4 \mathrm{~mm}, \sharp 2 \mathrm{~mm}, \sharp 1 \mathrm{~mm}, \sharp 0.5 \mathrm{~mm}, \sharp 0.25 \mathrm{~mm}$, $\sharp 0.125 \mathrm{~mm}$ and $\sharp 0.063 \mathrm{~mm}$. After the material was sieved uniformity coefficient $\left(C_{u}\right)$ and curvature coefficient $\left(C_{c}\right)$ were calculated and the grading curve was drawn (Fig. 1). From the progress of grading curve, tested material was classified as medium sand (MSa) with uniformity coefficient equal to 2.93 (uniform soil) and curvature coefficient equal to 1.04 (well - graded soil).

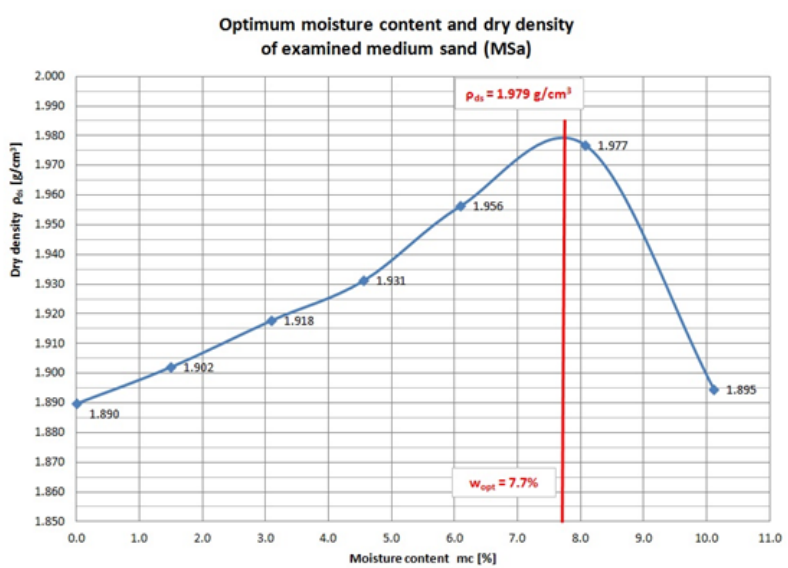

Fig. 2: Optimum moisture content and dry density of medium sand (MSa) obtained in Proctor apparatus test

\subsection{Test in Proctor Apparatus}

Tests in Proctor apparatus are performed to attain dry density and optimum moisture content of tested material. Proctor test in the present laboratory test was carried out in accordance to Polish standards [12]. Test was executed by implementing method I in small cylinder with volume of $1 \mathrm{dm}^{3}$ and light compaction rammer with weight of $2.5 \mathrm{~kg}$. The mass of specimen was equal to 3000.0 g. Examined material was placed inside the cylinder in three layers with equal thickness and each layer was compacted by 25 impacts of light compaction rammer. Test was performed in 7 series with different moisture content in medium sand - 0 \%, $1.51 \%, 3.09 \%$, $4.56 \%, 6.10 \%, 8.08 \%$ and $10.11 \%$. Results of Proctor tests are shown in Fig. 2. Optimum moisture content $w_{\text {opt }}$ was equal to $7.70 \%$ and was obtained with dry density $\rho_{d s}$ equal to $1.979 \mathrm{~g} / \mathrm{cm}^{3}$.

\subsection{Shear Test in Direct Shear Apparatus}

Direct shearing apparatus is designed to obtain shearing strength of cohesive and non - cohesive soils. The results of complete test are values of cohesion $(c)$, internal friction angle $(\varphi)$ as well as shearing strength of soil 13 . Measurements were divided in four groups determined by moisture content of the material - $1 \%$, $5 \%, 7.5 \%$ and $10 \%$, in each group measurements were executed in 5 series diversified by values of nominal stress - $55 \mathrm{kPa}, 110 \mathrm{kPa}, 165 \mathrm{kPa}, 220 \mathrm{kPa}$ and $275 \mathrm{kPa}$. Tests were carried out in square box 10 x $10 \mathrm{~cm}$. Every series was divided into two steps: consolidation step which last 3 minutes and main step in which direct shearing test was executed with velocity of $1 \mathrm{~mm}$ per minute. Every series ended as the horizontal displacement of specimen attained $20 \%$ of specimen's width. The lowest value of effective cohesion was obtained for 
the lowest moisture content $(1.00 \%-0.5 \mathrm{kPa})$ and the highest value for the maximum moisture content $(10.00 \%-4.4 \mathrm{kPa})$ (Tab. 1). It can be simply explained by higher values of interaction forces between respective grains of the material in moist than in dry material. Values of internal friction angles were in inverse proportion - increasing moisture content caused decrease in values of internal friction angle.

\subsection{Trial Loadings in Small - Scale Test}

The main concept for performing trial loadings is to simulate a realistic problem in smaller scale keeping the boundary conditions and stress paths in the medium. As a result there is a possibility to obtain the relationship between deformation and applied load 11. In presented initial tests trial loadings were executed on a special test stand composed of test cylinder $(76.8 \mathrm{~cm}$ height, $1.3 \mathrm{~cm}$ thick bottom, external diameter $54.2 \mathrm{~cm}$, internal diameter $51.6 \mathrm{~cm}$ ), wooden plate (external diameter $51.0 \mathrm{~cm}$, internal circle excision with diameter $10.5 \mathrm{~cm}$ ), steel loading plate (diameter $10 \mathrm{~cm}$, thickness $2.8 \mathrm{~cm}$ ), VSS plate hydraulic equipment, counterweight and concrete ballast blocks (Fig. 3). Test was executed for three moisture contents of medium sand $4.23 \% 6.49 \%$ and $8.76 \%$. Dimensions of elements of test stand and specimens dimensions were matched together taking into account model similarity conditions and scale effect between initial and destined test stand. Tested medium sand was placed inside the cylinder in two layers of total thickness equal to $31.2 \mathrm{~cm}$. Each layer was compacted by 35 impacts of heavy rammer (20 kg), 55 impacts of heavy compaction rammer used in Proctor test $(4.5 \mathrm{~kg}$ ) and 5 level - off impacts with heavy rammer $(20 \mathrm{~kg})$. On prepared two - layered surface wooden plate was placed and in the inner circle excision the steel loading plate was put. On the surface of wooden plate concrete ballast blocks were set. Concrete blocks of total weight equal to $79 \mathrm{~kg}$ imitate load of backfill consisting of $7.5 \mathrm{~cm}$ layer of concrete rubble and $8.3 \mathrm{~cm}$ layer of dolomite $0 / 31.5$. Wooden plate and ballast are crucial elements to prevent upheaval of material under applied load generated by VSS hydraulic equipment and counterweight. Vertical displacements were measured by dial gauge with measurement range 0-25 $\mathrm{mm}$ and $0.01 \mathrm{~mm}$ precision. Load was applied as for improved subgrade in $0.0 \div 200.0 \mathrm{kPa}$ range with $12.5 \mathrm{kPa}$ step, while values of vertical displacements at unloading were recorded in $50 \mathrm{kPa}$ steps. All specimens had the same load - unload sequence consisting of 4 applications of load and 4 unloading processes. Results of trial loadings are shown in Figs. $4-6$.

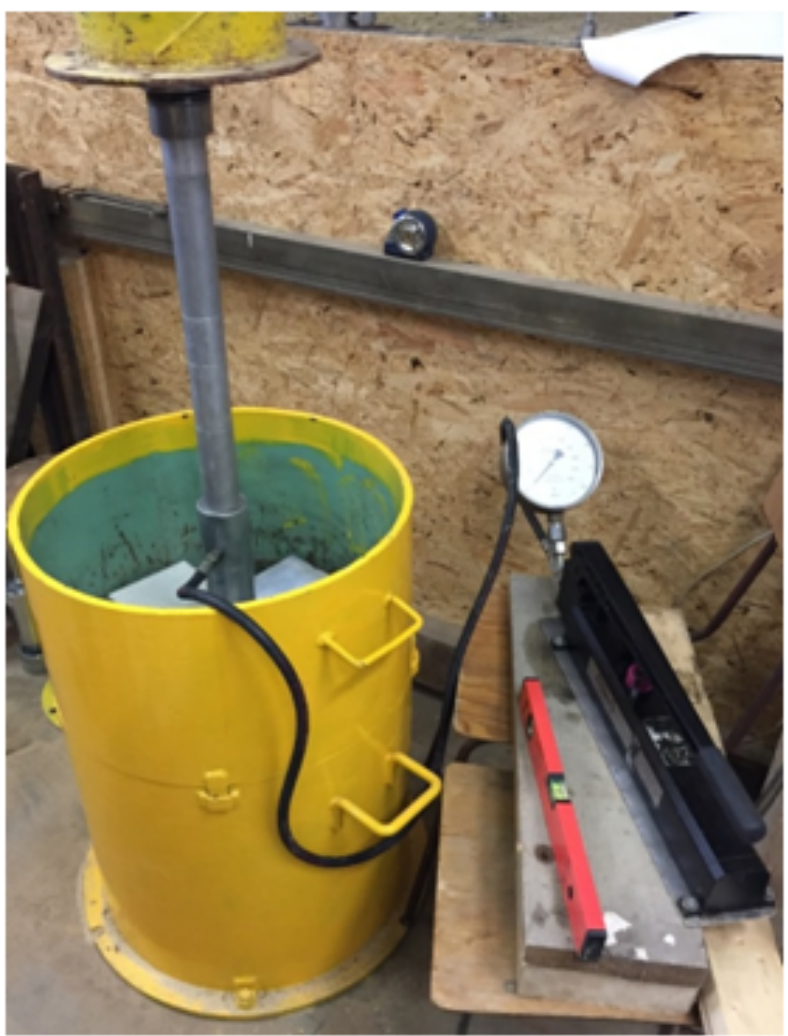

Fig. 3: Trial loading in small - scale test stand

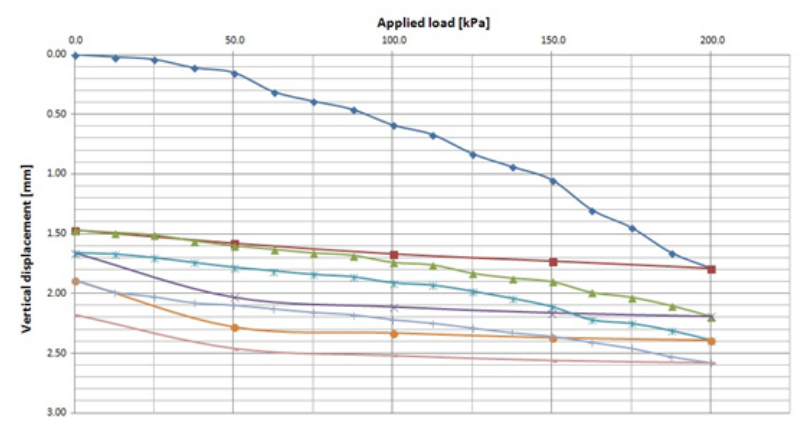

Fig. 4: Applied load - vertical displacement relationship for full test cycle of medium sand (MSa) with $6.49 \%$ moisture content

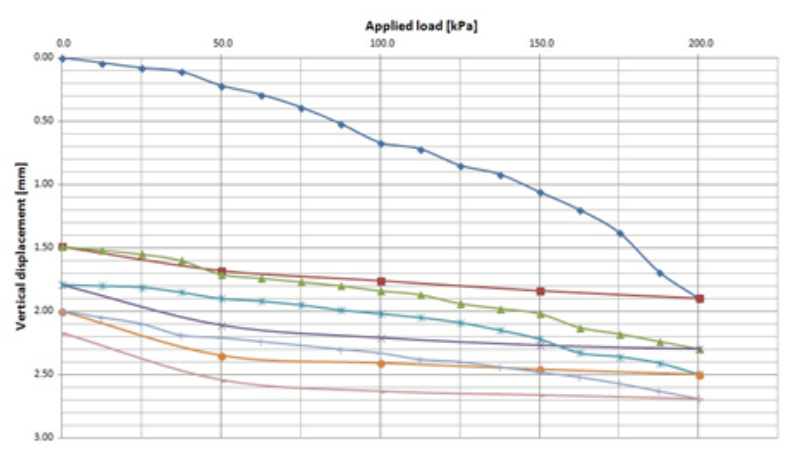

Fig. 5: Applied load - vertical displacement relationship for full test cycle of medium sand (MSa) with $6.49 \%$ moisture content 


\begin{tabular}{|c|c|c|c|}
\hline Group of measurements & Moisture content [\%] & Cohesion [kPa] & Internal friction angle [ $\left.{ }^{\circ}\right]$ \\
\hline 1 & 1.0 & 0.5 & 32.0 \\
\hline 2 & 5.0 & 2.4 & 31.5 \\
\hline 3 & 7.5 & 3.3 & 30.7 \\
\hline 4 & 10.0 & 4.4 & 29.9 \\
\hline
\end{tabular}

Tab. 1: Results of shear tests in direct shear apparatus

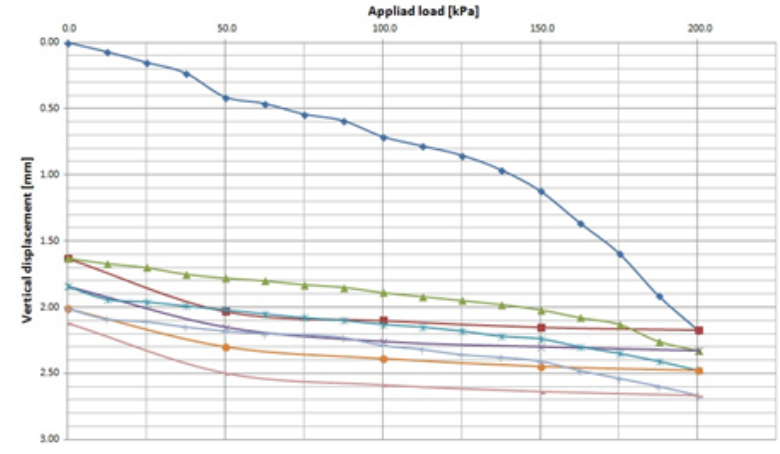

Fig. 6: Applied load - vertical displacement relationship for full test cycle of medium sand (MSa) with $8.76 \%$ moisture content

\section{Numerical Analyses}

In mechanistic approach the relationship between response of pavement structure (i.e. strain or deflection) and the physical parameters is described through a numerical model [14, 15]. Presented results of numerical analyses of small scale laboratory tests were attained by using Z_Soil 2014 software [10] in which the finite elements method (FEM) is incorporated. Before starting the back - calculation analyses studies aimed to obtain the best mesh density and impact of boundary conditions in small - scale tests were executed.

\section{1. $\quad$ Effect of Mesh Density and Diameter of Loading Plate}

Every numerical analysis has to be preceded by introductory tests to recognize correctness of prepared numerical model. Authors have investigated two different effects - influence of mesh density on values of vertical displacements and influence of diameter of loading plate on boundary conditions. To verify effect of mesh density on values of vertical displacements seven models were prepared using axisymmetry mode in $\mathrm{Z}$ Soil. In each model test cylinder filled with medium sand was prepared by using Coulomb - Mohr (C - M) model of soil. Models were diversified by the density of mesh in the vertical section along loading plate. Mesh sizes were equal to: 1 x $0.83 \mathrm{~cm}$ (model 2.1), $1 \times 1.25 \mathrm{~cm}(2.2), 1.95 \times 1.25 \mathrm{~cm}(2.3), 2.6 \times 1.25 \mathrm{~cm}$ (2.4), $2.84 \times 1.25 \mathrm{~cm}(2.4 \mathrm{a}), 1.95 \times 2.5 \mathrm{~cm} \mathrm{(2.5)} \mathrm{and}$ $2.6 \times 2.5 \mathrm{~cm}(2.6)$. Examples of mesh sizes are pre-

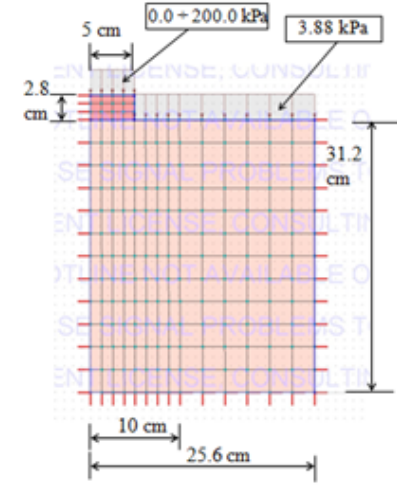

Model 2.4 - selected for further calculations

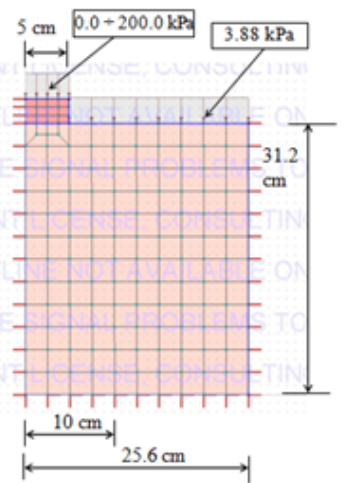

Model 2.6
Fig. 7: Examples of mesh density in model 2.4 and 2.6

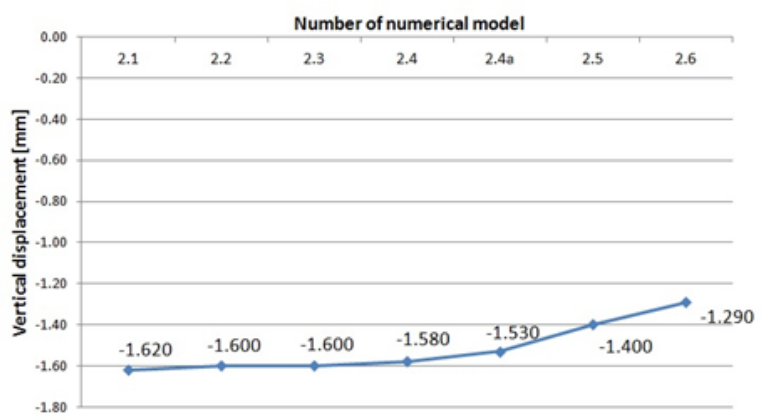

Fig. 8: Values of vertical displacements for analyzed numerical models

sented in Fig. 7. Values of vertical displacements carried out in the same loading and material conditions in the same finite element allowed to verify the effect of mesh density. For models $2.1 \div 2.4$ values of maximum vertical displacement were stabilized near $1.600 \mathrm{~mm}$ value as values for model $2.4 \mathrm{a} \div 2.6$ were notably lower (Fig. 8). For further calculations model 2.4 was selected, because in this model vertical displacements are at the stabilized level and the mesh density is thin, which allows to execute quicker calculations.

The second introductory test was recognition of loading plate diameter in accordance to boundary conditions. Three diameters of loading plate were tested: $10 \mathrm{~cm}$ (2.P.1), $20 \mathrm{~cm}(2 . P .2)$ and $30 \mathrm{~cm}$ (2.P.3). Validation of each model was obtained by calculating maximum horizontal stresses in the edge part of model, where the influence of applied load had to be unnotice- 


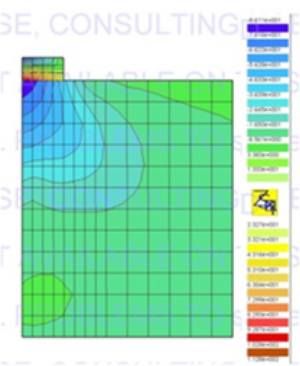

Map of horizontal stresses - model 2.P.1

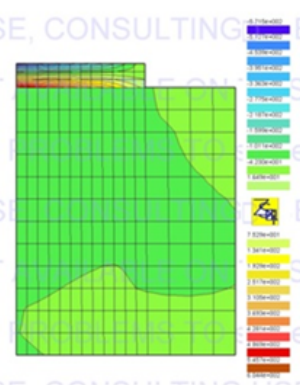

Map of horizontal stresses - model 2.P. 3
Fig. 9: Maps of horizontal stresses obtained in models 2.P.1 and 2.P.3

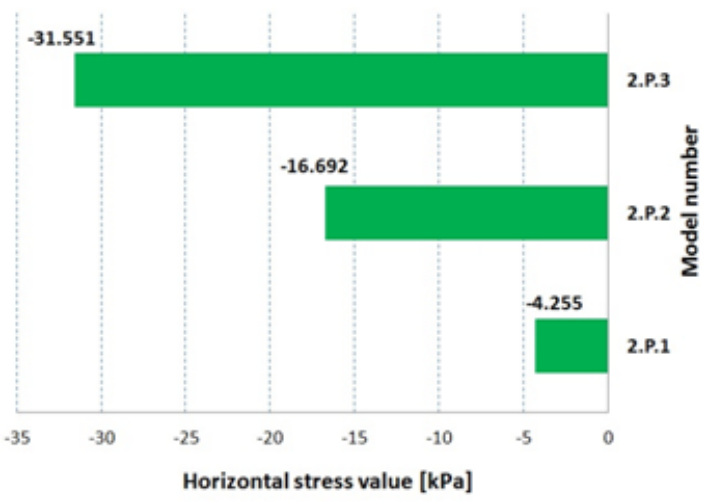

Fig. 10: Maximum horizontal stress value on the edge of each model

able (Fig. 9). Results of the investigation are shown in the Fig. 10. The lowest value of horizontal stress in the edge part of the model was obtained in model 2.P.1 where the smallest plate was used. In both 2.P.2 and 2.P.3 models values of stresses were respectively almost 4 times and 8 times higher. In further calculations plate with diameter of $10 \mathrm{~cm}$ was used.

\subsection{Numerical Analyses and Back - Calculation}

Numerical analyses were performed using model 2.4 for specimens with different moisture content as it was mentioned in paragraph 2.4., thus models were diversified in terms of model parameters - cohesion $(c)$, internal friction angle $(\varphi)$ and modulus of elasticity $(E)$. Parameters of models were obtained by using the back - calculation method. On the basis of experimental curves of loading - vertical displacement relationship model curves were stated by numerous iterations. The process of iteration ended while both experimental and model curves had the best match described by coefficient of determination R2 [16] and root mean squared
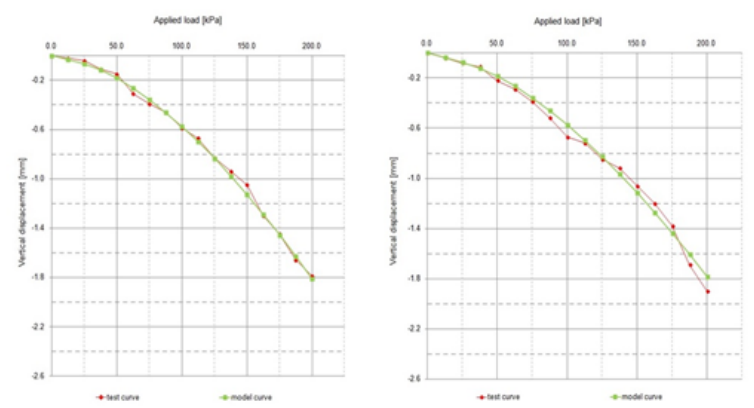

Fig. 11: Match between test and model curves for tested medium sand with $4.23 \%$ (left) and $6.49 \%$ (right) moisture content

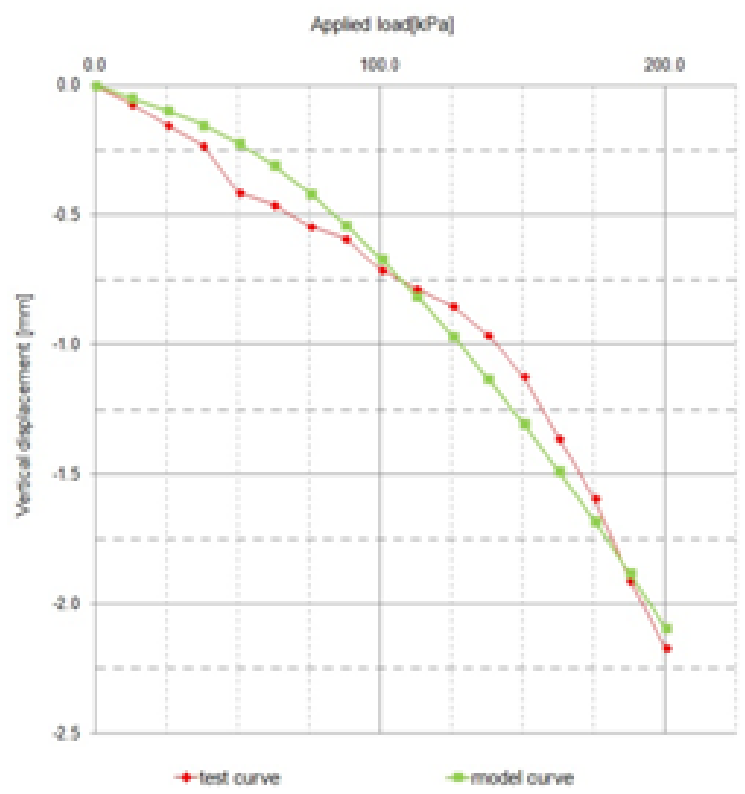

Fig. 12: Match between test and model curves for tested medium sand with $8.76 \%$ moisture content

error (RMSE) [18, 19, which enabled to state the parameters of Coulomb - Mohr model. Example of match between the test and model curves for moisture content equal to $8.76 \%$ is shown in Figs. 11- 12. Obtained values of cohesion, internal friction angle and modulus of elasticity are shown in Tab. 2.

Parameters of medium sand layer $(c, \varphi, E)$ stated with three different moisture conditions are acceptable as well as the match between test and model curves is satisfactory. In accordance to Tab. 1 cohesion and internal friction angle values obtained in numerical analysis are strongly connected with laboratory tests. For moisture content between $5.00 \div 7.50 \%$ values of cohesion vary between $2.4 \div 3.3 \mathrm{kPa}(2.4 \div 3.4$ in model $)$ and values of internal friction angle vary between 30.7 $\div 31.5$ degrees $(30 \div 31$ degrees in model $)$. Crucial difference in model parameters was obtained for moisture content under the value of optimum mositure content 


\begin{tabular}{|c|c|c|c|c|c|c|c|c|}
\hline \multirow{2}{*}{ Layer } & \multicolumn{6}{|c|}{ Parameters } & \multirow{2}{*}{$R^{2}$} & \multirow{2}{*}{$R M S E[\%]$} \\
\hline & $E[\mathrm{MPa}]$ & $c[\mathrm{kPa}]$ & $\phi\left[^{\circ}\right]$ & $\psi\left[{ }^{\circ}\right]$ & $\nu$ & $\gamma\left|\mathrm{kN} / \mathrm{m}^{3}\right|$ & & \\
\hline$M S a 31.2 \mathrm{~cm}$ & 21.0 & 2.4 & 30 & 0 & 0.3 & 19 & 0.997 & 3.02 \\
\hline$M S a 31.2 \mathrm{cn}$ & 18.5 & 2.9 & 31 & 0 & 0.3 & 19 & 0.997 & 5.44 \\
\hline$M S a 31.2 \mathrm{~cm} m c=8.76 \%$ & 14.8 & 3.4 & 31 & 0 & 0.3 & 19 & 0.974 & 10.74 \\
\hline
\end{tabular}

Tab. 2: Results of back - calculation of Coulomb - Mohr parameters of applied model in $\$$ Soil

(m - c equal to $4.23 \%-E=21.0 \mathrm{MPa})$ and above the value of optimum moisture content $(\mathrm{m}$ - c equal to $8.76 \%-E=14.8 \mathrm{MPa}$ ) where the value of modulus of elasticity decreased by $6.2 \mathrm{MPa}$.

\section{Discussion}

In the initial stage of laboratory and numerical tests particularly important are parameters obtained in direct shearing apparatus - cohesion $(c)$ and internal friction angle $(\varphi)$. Results obtained using procedures in accordance with [20] are the basis reference for results from back - calculation analysis. Series of trial loadings of medium sand with different moisture content executed in test cylinder allowed to back - calculate $c$ and $\varphi$ as well as values of modulus of elasticity $(E)$. Obtained values of internal friction angles and cohesion were close enough to values of the same parameters attained from direct shearing apparatus in similar moisture conditions of medium sand. Due to good consistency of results $(c, \varphi)$, the values of E modulus are reliable supplements of $\mathrm{C}-\mathrm{M}$ parameters describing the influence of moisture content on mechanical properties of tested sand. On the basis of presented results it can be stated that methodology of trial loadings and back - calculation is correct and can be used in further research. In evaluation of values of $\mathrm{C}-\mathrm{M}$ model parameters especially interesting fact is that values of internal friction angle and cohesion do not clearly vary in terms of variable moisture content. The same trend was observed in both shearing tests and back - calculation analyses. More noticeable differences were observed in values of modulus of elasticity $(E)$. Value of $\mathrm{E}$ for sand with $\mathrm{m}-\mathrm{c}=4.23 \%$ is equal to $21.0 \mathrm{MPa}$ and with $\mathrm{m}-\mathrm{c}=8.76 \%$ is equal to $14.8 \mathrm{MPa}$, what gives $6.2 \mathrm{MPa}$ difference $(30 \%)$. It seems that difference in values of modulus of elasticity around $30 \%$ is relatively small due to a $100 \%$ difference in moisture content. It is worth to mention that maximal and minimal values of $E$ were obtained respectively under and above the value of optimum moisture content.

\section{Conclusion and Final Remarks}

A comprehensive laboratory studies were undertaken to obtain key mechanical parameters of soils in loading conditions with different moisture content. Obtained values of cohesion, internal friction angle and modulus of elasticity were modeled using finite element method and back - calculated to attain analytical values of parameters.

Conclusions:

- Different moisture content affected the value of modulus of elasticity $(E)$, as well as the parameters of Coulomb - Mohr model. Value of $E$ was highest when the material contained low value of moisture (m - c $4.23 \%-E 21.0 \mathrm{MPa})$ and the highest when medium sand was in high moisture conditions (m - c $8.76 \%$ - E $14.8 \mathrm{MPa}$ ). The difference of $E$ values in accordance with moisture content was around $30 \%$.

- The lowest values of cohesion were obtained for "dry" material the highest for "moist" material, but for internal friction angle the trend was inverse - the lowest values were obtained for "moist" material and the highest for "dry" material.

- Internal friction angle and cohesion were parameters on which the influence of variable moisture conditions was not clearly observed. The most affected mechanical parameter was modulus of elasticity.

- Difference around $30 \%$ in $E$ values with simultaneous difference of moisture content by $100 \%$ must be verified by further research consisting of field tests, laboratory tests, numerical analyses and back - calculation analyses.

- Results of initial laboratory tests shown in this article are only the preface to main laboratory tests and attend to develop further research program.

\section{References}

[1] DORE, G. and J.P. BILODEAU. Influence of moisture content on the resilient modulus of 
base granular materials. In:Materials of Annual Conference of the Transportation Association in Canada. 2011, Edmonton, Canada.

[2] ROBERTSON, R. and J. SIEKMEIER. Determining material moisture characteristics for pavement drainage and mechanistic empirical design [online]. Minnesota Department of Transportation Research Bulletin, Materials and Road Research 09, USA, 2002.

[3] SAAD, B.N. Analysis of excess water impact on the structural performance of flexible pavements. International Journal of Pavement Engineering. 2014, vol. 15, No. 5, pp. 409-426. DOI: .

[4] ROKITOWSKI, P. and M. GRYGIEREK. Influence of high water contents on pavement layers stiffness caused by flooding. In: Transactions of the VSB - Technical University of Ostrava, Civil Engineering Series. 2016, vol. 16, iss. 1, DOI: .

[5] SALOUR, F. and S. ERLINGSSON. Pavement unbound materials stiffness-moisture relationship during spring thaw. Cold Regions Engineering 2012: Sustainable infrastructure development in changing cold environment. (Conference Paper), ASCE, 2012.

[6] ROKITOWSKI, P. Wybrane zagadnienia zwiazane z ocena wplywu wilgotnosci na stan nawierzchni drogowej. Zarys wybranych zagadnien $\mathrm{z}$ inzynierii ladowej - praca zbiorowa pod redakcja J. Bzowki. Gliwice, 2016, str. 175-182.

[7] ERLINGSSON, S. Impact of water response on the response and performance of a pavement structure in an accelerated test. Road Materials and Pavement Design. 2010, vol. 11, iss. 4, ppt. 863-880. DOI: .

[8] MIECZKOWSKI, P. and B. BUDZINSKI. Influence of excessive moisture in the subgrade on the durability and load-bearing capacity of road pavements. In: IOP Conference Series: Materials, Science and Engineering. 2018, vol. 356, Conference 1, DOI: .

[9] SAEVARSDOTTIR, T.H. and S. ERLINGSSON. Water impact on the behaviour of flexible pavement structures in an accelerated test. Road materials and pavement design. 2013, vol. 14, iss. 2, pp. 256-277, DOI: .

[10] ZSoil manual, Elmepress and Zace Services Limited, Lausanne, Switzerland, 2014.

[11] PIECZYRAK, J. Corporation. Defining the parameters of subsoil models on the basis of trial loadings. Research Notebooks of Silesian University of Technology no. 91, Gliwice, 2001 (in Polish).
[12] PN-EN 13286-2:2010 Unbound and hydraulically bound mixtures - Part 2: Dry density and moisture content laboratory methods - Compaction by Proctor method. 2010 (in Polish).

[13] BZOWKA, J. et al Communication geotechnics. ISBN 978-83-7880-025-5, Silesian University of Technology Publishing, Gliwice, 2013 (in Polish).

[14] AMIRI, $H$. et al Investigation of impact of moisture variation on response of pavements through small-scale models. Journal of materials in civil engineering. Berlin, October 1, 2009, vol. 21, no. 10, pages 553560, ISSN 0899-1561/2009/10-553-560, DOI: 10.1061/(ASCE)0899-1561(2009)21:10(553).

[15] MAZARI, M. et al. Comparison of numerical and experimental responses of pavement systems using various resilient modulus models. Soils and Foundations. 2014, no. 54, pp. 36-44, DOI: 10.1016/j.sandf.2013.12.004.

[16] KWIECIEN, S. Calibration and verification of numerical model of ground improved by dynamic replacement. Numerical methods in geotechnical engineering. Proceedings of the Seventh European Conference on Numerical Methods in Geotechnical Engineering, Trondheim. Norway, 2-4, June 2010. Ed. by T. Benz and S. Nordal, pp. 839-843.

[17] GORNAS, P. and A. POZARYCKI. et al. Selected properties of FEM numerical models for inverse analysis of road pavement structures. Roads and bridges. 2014, vol. 13, pp. 203-222.

[18] GORNAS, P. and A. POZARYCKI. et al. Selected properties of FEM numerical models for inverse analysis of road pavement structures. Roads and bridges. 2014, vol. 13, pp. 203-222.

[19] GUZZARLAPUDI, S.D., ADIGOPULA, V.K. and R. KUMAR. eComparative study of flexible pavements layers moduli backcalculationusing approximate and static approach. Materials Today: Proceedings 4. ICEMS 2016, pp. 9812-9816.

[20] PKN-CEN ISO/TS 17892-10 Geotechnical tests. Laboratory tests of soils. Part 10: Direct shearing apparatus test, 2010 (in Polish). 